\title{
FABULAÇÕES JUNTO À LITERATURA DE "O PEQUENO PRÍNCIPE": ESCRITAS QUE PEDEM PASSAGEM DE VIDA
}

Rafael Agatti Durante ${ }^{1}$

Angélica Neuscharank ${ }^{2}$

Resumo: Este texto apresenta um recorte do trabalho de conclusão de curso em Licenciatura - Artes Visuais, onde foram realizadas algumas experimentações com o livro ' $O$ Pequeno Príncipe' (SAINT-EXUPÉRY, 2014). Trata-se da problematização dessa literatura junto a noção de fabulação (DELEUZE, 2011), traçando um caminho de pensamento que se articula com as ideias propostas por Deleuze e Guattari (2010) sobre filosofia, literatura e arte, que possibilitam escapar de modos lineares de compreender as narrativas e tempos de uma história, nos reinventando diante dos modelos e dos elementos considerados principais de um livro tão conhecido como esse, para dar lugar às imagens, passagens e acontecimentos vistos como secundários e aprender com as existências mínimas de escritas que pedem passagem de vida. Com este propósito, buscamos compartilhar as experiências docentes como resultados de uma pesquisa desenvolvida com estudantes de uma turma de sexto ano do ensino fundamental e uma turma de ensino não-formal em uma ONG. Assume-se a fabulação enquanto método de pensamento para operar com a referida literatura na educação como um procedimento de saúde (DELEUZE, 2011), a qual nos faz estar e habitar o mundo pandêmico de outros modos, nos manter vivos pelo ininterrupto movimento de aprender com o que lemos e fabular. Por fim, apresentamos um percurso de experimentação com a literatura, onde foi possível invencionar frases, comer letras, criar livros, envelopes, planetas e 'carneiros através de caixas'.

Palavras-chave: Literatura; O Pequeno Príncipe; Fabulação; Educação.

\section{MANUFACTURES OVER THE LITERATURE OF “THE LITTLE PRINCE”: WRITINGS THAT REQUIRE THE LIFE PASSAGE}

\begin{abstract}
This text presents an excerpt from the course conclusion work in Graduation Visual Arts, where some experiments were carried out with the book 'Little Prince' (SAINTEXUPÉRY, 2014). It deals with the problematization of this literature together with the notion of fabulation (DELEUZE, 2011), tracing a path of thought that articulates with the ideas proposed by Deleuze and Guattari (2010) about philosophy, literature and art, which make it possible to escape in linear ways to understand the narratives and times of a story, reinventing ourselves before the models and elements considered main in a book as well known as this, to give way to the images, passages and events seen as secondary and to

\footnotetext{
${ }^{1}$ Mestrando em Educação, Linha de Pesquisa Educação e Artes - LP4, pela Universidade Federal de Santa Maria. Endereço postal: Av. Roraima, № 1000, Casa do Estudante Universitário CEU III, Bloco 51, apto. 5112, Bairro Camobi, Cep 97105-900 - Santa Maria. Endereço eletrônico: rafa.agatti@yahoo.com.br

${ }^{2}$ Doutora em Educação, Linha de Pesquisa Educação e Artes - LP4, pela Universidade Federal de Santa Maria. Endereço postal: Rua Duque de Caxias, no 1943, apto. 301, Centro, Cep 97015-190 Santa Maria. Endereço eletrônico: angelicaneuscharank@gmail.com
} 
learn from the minimal existences of writings that ask for life passage. For this purpose, we seek to share the teaching experiences as a result of a research developed with students from a sixth grade class of elementary school and a non-formal class from an NGO. Fabulation is assumed as a method of thinking to operate with the aforementioned literature on education as a health procedure (DELEUZE, 2011), which makes us live and inhabit the pandemic world in other ways, keeping us alive through the continuous movement of learning with what we read and fabulous. Finally, we present a journey of experimenting with literature, where it was possible to invent phrases, eat letters, create books, envelopes, planets and 'sheep through boxes'.

Keywords: Literature; Little Prince; Fabulation; Education.

\section{Os encontros que fazem brotar, linhas de um começo}

Intentamos apresentar neste artigo algumas experiências docentes oriundas de um trabalho de conclusão de curso em Licenciatura - Artes Visuais que procurou operar com a fabulação enquanto método de pesquisa para possibilitar outros encontros com a literatura de 'O Pequeno Príncipe' (SAINT-EXUPÉRY, 2014) e forjar movimentos de olhar não somente para o texto, os/as personagens, mas também para as aquarelas e demais visualidades que o compõe, bem como as múltiplas entradas diante dos desfechos da narrativa.

Junto a essas experiências nos colocamos a pensar na literatura como um procedimento de saúde (DELEUZE, 2011), a qual nos faz estar e habitar o mundo pandêmico de outros modos, nos manter vivos pelo ininterrupto movimento de aprender com o que lemos e fabular. Para isso, a literatura seria um esforço de criação, de inventar e produzir possibilidades de vida, as quais nos tiram de um lugar comum e nos forçam a uma condição de espera e atenção aos modos de existência mínimos, implicando uma reconfiguração acerca das percepções cotidianas, das relações, dos encontros com o que lemos e escrevemos.

Com autoria do escritor, ilustrador e piloto francês Antoine de Saint-Exupéry (1900-1944), 'O Pequeno Príncipe' foi escrito em 1943 durante a Segunda Guerra Mundial. Em suas linhas de escrita conta a história de uma viagem realizada pelo narrador/personagem, onde no decurso de um voo é obrigado por uma pane em seu avião a realizar um pouso no deserto do Saara. Após uma noite isolado é desperto por um menininho de cabelos dourados cor de trigo, explorador e aventureiro que se mostrava muito curioso e não dava grandes explicações sobre o que the era 
Criar Educação, Criciúma, v. 9, nº 3, ago/dez. 2020 - PPGE - UNESC - ISSN 2317-2452

questionado. Vindo de outro planeta um pouco maior que uma casa, decide contar ao piloto suas aventuras pelos asteroides 325, 326, 327, 328, 329 e 330 (SAINTEXUPÉRY, 2014) em busca de amigos e conhecimento, narra seus encontros com reis, bêbados, homens de negócios, homens solitários, raposas e cobras, até sua chegada na Terra.

Nos enlaces com essa literatura compartilhamos a possibilidade de pensar uma docência e uma educação pela fabulação, partilhando as experiências de "manter o movimento, constante, de invenção de diálogos, de materialidades, de intervenções, de vida" (BARIN, 2019, p. 103) em dois espaços educacionais distintos: uma turma de sexto ano no ensino fundamental e uma turma de ensino não-formal em uma Organização Não Governamental (ONG) ${ }^{3}$, onde realizamos cerca de quinze encontros com um número aproximadamente de vinte e quinze estudantes. Esses momentos foram registrados a partir da captura de imagens feitas com celular e, também, através da criação do Diário da Prática Pedagógica - DPP (OLIVEIRA, 2011; 2014), o qual foi produzido concomitantemente aos encontros com as turmas.

Nossa intenção não foi apresentar/trabalhar com essa narrativa literária de modo cronológico, seguir os passos dos/as personagens, tampouco fazer uma crítica ao livro, exibir soluções, receitas ou modos mais assertivos de trabalhá-lo no contexto educacional, mas sim apresentar outras perspectivas para abordá-lo, maneiras que sejam diferentes da função moralizante e de autoajuda que lhe é atribuída, que busquem experimentar e olhar para o que pode nos levar à outras movimentações, àquilo que, muitas vezes, 'escapa' da ordem do previsível e controlável. A proposta é pensar com a literatura, diferente de pensar sobre a literatura.

Para tanto, apresentamos algumas atividades que foram realizadas com os/as estudantes, dentre as quais: interferências com tinta, cola nas páginas de um livro, que denominamos livro de artista (SILVEIRA, 2001); distribuição de envelopes com uma frase de 'O Pequeno Príncipe' repetida e fragmentada para que

\footnotetext{
${ }^{3}$ As Organizações Não Governamentais (ONGs) são instituições sem fins lucrativos, cujo trabalho desenvolvido tem como foco a atuação social em comunidades, cidades ou países que possuem áreas consideradas carentes ou vulneráveis.
} 
inicialmente ela fosse reproduzida tal qual na história e depois desmontada, sendo possível brincar com as palavras soltas, criando outras composições; disposição de algumas ilustrações que fazem parte da narrativa, propondo a fragmentação das mesmas em diferentes tamanhos e formatos para que se criasse outra imagem; realização de um desenho, onde no começo era possível copiar uma ilustração do livro colocando a folhas sobre a imagem e em certo momento o livro seria 'roubado', ficando a cargo dos/as estudantes criar outros/as personagens a partir dos traços esboçados; retomada da montagem das imagens fragmentadas, recortando novamente para, dessa vez, unir com linha e agulha, costurando outras figuras, imagens e personagens.

Sabemos que no contexto da educação, trabalhar com 'O Pequeno Príncipe' passou a ser algo corriqueiro. Por ser comumente relacionado a uma moral com ênfase sobre os valores humanos, esse livro 'caiu no gosto popular' em virtude da narrativa que apresenta várias respostas para a indagação 'que mensagem o livro nos passa?'. Assim acontece, muitas vezes, com os filmes que são baseados em livros, pois também se utilizam desse viés com o intuito de propor algumas atividades que estejam centradas no campo do lúdico ou que eduquem para uma valorização: dos amigos, da família, da escola, das coisas simples da vida e de outros tantos elementos que 'precisam' ser 'ensinados pela escola'. Outro aspecto é a abordagem transdisciplinar, cuja ênfase também está em um produto resultante do trabalho de duas ou mais disciplinas que se juntam para explorá-lo, por exemplo arte e geografia, onde na primeira é estudada a história e os/as personagens, reproduzindo algumas ilustrações, enquanto na segunda o livro é utilizado para representar o sistema solar, tendo em vista a viagem por inúmeros planetas que o príncipe realiza.

Quando essa literatura é tomada por um pensamento genérico, algumas atribuições são reforçadas no senso comum, como as de que 'O Pequeno Príncipe' seria aparentemente um livro destinado para crianças ou um gênero de 'autoajuda' para os adultos, isto é, uma escrita que supostamente produziria um discurso específico para esses dois grupos e que apresentaria condições que levariam as pessoas a realizarem mudanças em suas vidas, seja através da busca pela 
felicidade, da reflexão individual, de conhecimento sobre as relações com o outro, ou ainda, a partir de uma fetichização de passagens e personagens. Quem nunca ouviu a famosa frase "Você se torna para sempre responsável por aquilo que cativou" (SAINT-EXUPÉRY, 2014, p. 74); e em quantas tatuagens, canecas, joias, materiais escolares e roupas estão reproduzidas as ilustrações do menininho com a raposa, da rosa, da jiboia que engoliu um elefante?

Assim, a literatura aqui é tratada como movimento de criar vidas possíveis, de passagens de vida, de devir, travessias, da potência da arte de escrever e ler como uma tentativa de libertar a vida daquilo que a aprisiona, de traçar linhas de fuga para as prisões existenciais, que em tempos de isolamento social se acentuaram. Para Deleuze (2011) a criação literária não é um comunicar, mas antes um resistir diante das situações de opressão e de qualquer tipo de pensamento fascista. A literatura é uma saúde.

Ressaltamos que não se trata da busca por "ideias justas" (DELEUZE; GUATTARI, 1995, p. 36) sobre o livro ou sobre um modo 'melhor' de explorá-lo, mas o que intentamos, assumindo os riscos das errâncias que podem incorrer, é criar “justo uma ideia” (DELEUZE; GUATTARI, 1995, p. 36) de repensar, problematizar e expandir possibilidades teóricas, epistemológicas e metodológicas de docências e da literatura ser abordada no contexto da educação e das artes visuais, a partir do apontamento de algumas situações que consideramos banalizações da obra, compartilhando experimentações com a referida literatura.

Nesse sentido, o presente artigo foi se tramando pela problemática de pensar: como operar com a literatura de Saint-Exupéry (2014) na educação a partir de outros movimentos e junto a noção de fabulação? Compartilhamos os acontecimentos que povoaram os encontros com a literatura de 'O Pequeno Príncipe' acolhida em três versões diferentes - 'O Pequeno Príncipe' (SAINTEXUPÉRY, 2014), 'O Pequeno Príncipe: livro pop-up' (SAINT-EXUPÉRY, 2015) e 'O Pequeno Príncipe em Cordel' (LIMEIRA, 2017) - em conjunto com os/as estudantes dos espaços educativos em que a pesquisa foi desenvolvida. Por fim, apresentamos algumas considerações sobre tais experiências e as suas ressonâncias no processo 
Criar Educação, Criciúma, v. 9, n 3, ago/dez. 2020 - PPGE - UNESC - ISSN 2317-2452

de formação docente, os 'possíveis' que nos possibilitaram invencionar frases, comer letras, criar livros, envelopes e planetas.

\section{Oper[ar] com a fabulação}

A fabulação pediu passagem e permitiu algumas experimentações com a literatura de Saint-Exupéry, descobrir alguns gigantes e também fugir de modelos, escapar de formas, formatos e concepções já estabelecidas. Nossa aposta com essa noção não é para contar lembranças, sonhos e viagens, nem para impor métodos ou receitas. Oper[ar] com a fabulação foi um movimento necessário para fazer brotar uma vida possível em meio a tudo o que aprisiona, ao que impede de sair o grito, ao que trava a garganta e toma o fôlego, forçando um estado de latência para propor uma tentativa de enunciar um "caso de devir, sempre inacabado, sempre em via de fazer-se, e que extravasa qualquer matéria vivível ou vivida" (DELEUZE, 2011, p. 11).

Com a fabulação nos encontramos com elementos de 'O Pequeno Príncipe' que possuem menos destaque na história, como por exemplo, o pôr do sol, a única flor no deserto, o jardim de rosas e tentamos 'sacudir' algo, não em outro mundo ou lugar, nem em um mundo utópico. A escolha pelo tempo do aqui e agora se faz em aliança com Deleuze (2013), o qual escreve que utopia não é um bom conceito por remeter a um mundo dos sonhos, distante do mundo em que se vive. Segundo o autor, há antes uma fabulação que é comum ao povo e a arte, isto é, inventar um povo que falta, um povo menor, coletivo, que não segue modelos e necessita da criação para sobreviver em meio a um poder majoritário.

Os filósofos franceses Gilles Deleuze e Felix Guattari tomam a fabulação como uma noção, pois para os autores os conceitos são do campo da filosofia e quando discorrem sobre a fabulação falam sobre os campos das artes, mais precisamente da literatura e do cinema, posição que passamos a adotar durante o processo de pesquisa e elaboração desta escrita.

Quanto a palavra fabulação, ao problematizá-la com os/as estudantes percebemos que a confundiam com a ideia de fábula, talvez pela semelhança morfológica das palavras. Contudo, a fabulação difere-se dessa noção, pois a fábula 
é caracterizada pela narração - começo, meio, fim - de situações vividas por animais, mas que fazem alusão a situações humanas, explicando certos comportamentos e situações da vida cotidiana com o objetivo de transmitir uma certa moral.

Já a fabulação, ao invés de se preocupar com uma linguagem direta que quer comunicar e ser compreendida, está mais atenta aos outros modos de operação da linguagem que possam confundir essa ordem lógica da comunicação, fazendo "[...] a língua gritar, gaguejar, balbuciar, murmurar em si mesma" (DELEUZE, 2011, p. 141) para que outras possibilidades sejam criadas e se afastem dos modelos, dos universais. Com essa noção é possível "traçar para a linguagem uma espécie de linha de fuga" (DELEUZE, 2013, p. 58) que produz movimentos de dialogar sem dar ordens, sem representações de algo ou alguém, de permitir falar aqueles/aquelas que não têm esse direito na luta contra um poder dominante, de criar movimentos de resistência ao que chega, confina e impõe um 'novo normal', ao que nos força encontrar outros modos de manter o diálogo, busc[ar] em outros possíveis modos de se afetar.

Deleuze e Guattari (2017) em sua obra 'Kafka: por uma literatura menor' propõem uma aproximação da noção de fabulação com o conceito de literatura menor. Para esses autores, "uma literatura menor não é a de uma língua menor, mas antes a que uma minoria faz em uma língua maior" (DELEUZE; GUATTARI, 2017, p. 35), ou seja, os movimentos de resistências de povos marginalizados que estão as margens e que encontram na criação algo que ainda não está dado, que não existe e que acontece no coletivo.

O que é preciso é pegar alguém que esteja 'fabulando', em 'flagrante delito de fabular'. Então se forma, a dois ou em vários, um discurso de minoria. Reencontramos aqui a função da fabulação bergsoniana... Pegar as pessoas em flagrante delito de fabular é captar o movimento de constituição de um povo (DELEUZE, 2013, p. 161).

Nesses delitos fabulatórios nos encontramos com uma das principais características da fabulação: seu viés totalmente antinarrativo, onde há uma despreocupação - e até diríamos uma desobrigação - com o tempo cronológico. Com essa noção é possível (re)inventar com o que se tem, falar de algo que não 
está pronto, que nos movimenta a criar novos modos de existência, novas maneiras de sentir e agir, criar linhas de fuga (DELEUZE; PARNET, 1998) nos padrões impostos para uma aula, para os exercícios, para os modos de organização da sala e das maneiras de estar professores/professoras e de estar no mundo.

Assim, durante o processo de construção da pesquisa, procuramos sair do uso da língua como informação, representação, transmissão de ideias prontas e, ao propor o movimento de fabular, borramos com as margens que separam a linguagem escrita, verbal e visual. Desacomodamos a literatura de 'O Pequeno Príncipe' (SAINT-EXUPÉRY, 2014) de sua função usual e comum para pensarmos nos atravessamentos com a literatura nas aulas de artes visuais e produzir outras coisas com ela e junto aos/as estudantes.

Nesse percurso propusemos que 'O Pequeno Príncipe' estivesse em variação e que fosse olhado para o que estava ali, mas que passava despercebido. Nessas costuras, nesse ir e vir, a fabulação possibilitou olhar para o livro, os/as personagens, as frases, a escrita de outros modos e na companhia dessa literatura lançamos convites aos encontros com o desconhecido, com o novo, com o que pouco era visualizado ou notado.

Desse modo, considerando que o referido livro muitas vezes é tomado como 'modelo', repleto de significados prontos que muitas pessoas têm acesso da mesma forma, pelas mesmas imagens e fragmentos, questionamos: Como então fugir das famosas frases e ilustrações contidas no decorrer da história e reproduzidas de tantas maneiras distintas que tornam o livro um clichê? Já de antemão afirmamos que nosso propósito não é fugir do livro, mas sim produzir movimentos que gerem desconforto, que se distanciem do que já foi realizado tantas vezes com ele, com os elementos que ele nos oferece, fazer com "que a própria variação não deixe de variar, quer dizer, que ela passe efetivamente por novos caminhos sempre inesperados" (DELEUZE, 2010, p. 60), produzindo borbulhas, fendas na linguagem e nessa literatura.

Para Deleuze a literatura é uma saúde e "toda obra é uma viagem, um trajeto, mas que só percorre tal ou qual caminho exterior em virtude dos caminhos e trajetórias interiores que a compõem, que constituem sua paisagem ou seu 
Criar Educação, Criciúma, v. 9, № 3, ago/dez. 2020 - PPGE - UNESC - ISSN 2317-2452

concerto" (DELEUZE, 2011, p. 10). No primeiro capítulo de 'Crítica e Clínica' (DELEUZE, 2011) o autor afirma que escrever não é uma ação impositiva, tampouco uma forma de expressão a uma experiência vivida, pois a literatura estaria antes a serviço do informe e do inacabamento, dos devires.

Assim, escreveríamos como tentativa de libertar a vida de determinados postulados: "escreve-se sempre para dar a vida, para libertar a vida aí onde ela está aprisionada, para traçar linhas de fuga" (DELEUZE, 2013, p. 180). Nessa passagem, Deleuze faz repensar sobre o suposto exercício de 'dar vida a escrita', invertendo esta ação, já que para ele e para nós é a escrita que possibilita traçar linhas de fuga e outros modos de existência, pois escrever é um caso de devir em vias de fazer-se, sempre inacabado, trasbordando qualquer experimento de captura do vivível ou da matéria vivida. As escritas cavam sulcos nas passagens de vida, nos processos que atravessam a experiência do vivido. "A escrita é inseparável do devir: ao escrever, estamos num devir-mulher, num devir-animal ou vegetal, num devir-molécula, até num devir-imperceptível" (DELEUZE, 2011, p. 11).

Por isso, a língua tem de alcançar desvios dos modelos e modos de existência majoritários, sejam desvios femininos, animais, crianceiros, moleculares... a literatura só começa a nascer em nós quando destitui o poder do 'eu', instalando o artigo indefinido, o neutro, porque escrever não tem relação com contar as próprias lembranças das nossas viagens, amores e lutos, sonhos e fantasmas (DELEUZE, 2011). E cabe lembrar que não se escreve com as próprias neuroses, pois elas não são passagens de vida, mas são doenças, estados que interrompem e impedem a vida em sua expansão. Com efeito, a doença é a parada no processo e a literatura um empreendimento de saúde.

"Qual saúde bastaria para libertar a vida em toda parte onde esteja aprisionada pelo homem e no homem, pelos organismos e gêneros e no interior deles?" (DELEUZE, 2011, p. 14). A saúde como literatura, como escrita, consistiria em inventar um povo que falta, a partir e junto com a função fabuladora. Esse povo, um povo por vir, não seria um povo dominante, mas menor, formado por um devirrevolucionário. "Talvez ele só exista nos átomos do escritor, povo bastardo, inferior, dominado, sempre em devir, sempre inacabado" (DELEUZE, 2011, p. 15). Ainda, 
bastardo não por designação de um estado de família, mas pelo processo ou à deriva das raças.

Nesses movimentos, afirmamos junto ao filósofo Deleuze (2011) que não há literatura sem fabulação e que a mesma não consiste em imaginar nem em projetar um 'eu', mas atingir, sobretudo, os devires ou potências de criação de uma saúde, ou seja, invenção de um povo por vir, de possibilidades de vida e visibilidade de existências mínimas não reconhecidas ou catalogadas. Escrever, portanto, para criar mundos, para inventar uma espécie de língua estrangeira, que não é uma outra língua, tampouco um dialeto regional redescoberto, mas um devir-outro da língua, uma minoração da língua maior que possa nos arrastar a uma linha de feitiçaria que nos faz fugir ao sistema dominante.

\section{O giro da roldana, movimentos necessários}

Nos encontros com os/as estudantes nas escolas a fabulação esteve presente e permitiu movimentos de criações. Contudo ela nem sempre se mostrou ativamente, aparecendo mais em alguns dias, se expondo timidamente em outros. Nos primeiros contatos com as turmas apresentamos 'O Pequeno Príncipe' e comentamos que nos próximos encontros seriam abordadas questões e atividades relacionadas a essa literatura. Entre os/as estudantes a euforia era grande e os olhos brilhavam, tamanha repercussão dessa literatura junto aos/as adolescentes, ao passo que também percebíamos que crescia a expectativa em trabalhar com a história tal como é contada no livro, com a raposa, o príncipe, a rosa, as frases tão habituais, enfim, tudo o que já vimos e ouvimos várias e repetidas vezes.

Assim eram nossas conversas iniciais: '- Posso começar contando a história?', dizia um. Já outros/as com mais proximidade com esse livro e até mesmo com os filmes exclamavam: '- Eu já sei o final, o príncipe morre!'. Os personagens principais, como o príncipe, a raposa, o carneiro, a cobra engolindo o elefante também eram velhos conhecidos dos/as estudantes. Percebemos que durante as atividades propostas, havia certa insistência e um comodismo em produzir os trabalhos com essas figuras que já eram corriqueiras. Contudo, nossa intenção era desacomodar, desmontar as narrativas tão arraigadas nos discursos referentes ao 
livro 'O Pequeno Príncipe' para "potencializar a fabulação" (BARIN, 2019, p. 59). Esse era o momento de fugir da cronologia imposta, dos modos 'certos' de ler e abordar as atividades com essa literatura, os personagens, as passagens e as ilustrações.

O movimento que realizamos para adentrar na literatura foi semelhante aos trens que carregavam blocos de mil pessoas, ora para a esquerda, ora para a direita (SAINT-EXUPÉRY, 2014) indo por caminhos tortuosos. Nos interessou sacudir e deslocar as turmas de suas zonas de conforto, provocando-os/as a fugir do lugar cômodo ao optar por trabalhar com uma imagem contida na metade do livro por exemplo, ou outra não tão conhecida, ou por fragmentos de escrita sem grandes repercussões e significados.

Apostamos também na retirada do menininho viajante, figura central da história que raramente aparecia em nossos encontros e quando adentrava à sala de aula era sempre para outras movimentações. Esse movimento de 'subtração' de certos personagens e passagens da obra esteve amparado conceitualmente no texto produzido por Deleuze 'Um manifesto de menos', onde pensa a obra de Carmelo Bene (1937-2002), um ator, dramaturgo, encenador e cineasta italiano que se destaca por produzir amputações em peças de teatro consideradas clássicas. As subtrações de personagens centrais de histórias, de cenas amplamente conhecidas, acabam por produzir algo inesperado (DELEUZE, 2010), como por exemplo, na peça Romeu e Julieta de Shakespeare, em que Romeu, personagem principal, é neutralizado e em seu lugar vê-se o crescimento de Mercúrio, que antes era apenas uma virtualidade da peça original, constituindo-se, assim, uma nova peça.

Constatamos ao olhar para nossos planos de aula e também para a realização de algumas práticas nas escolas, que os recortes realizados e muitas das escolhas feitas em relação ao 'O Pequeno Príncipe' foram 'ao modo Bene', pois amputamos os seguintes personagens: o príncipe, a raposa, o carneiro, a rosa, a cobra, a cobra engolindo o elefante, além de fragmentos considerados tão importantes, como: "O essencial é invisível aos olhos" (SAINT-EXUPÉRY, 2014, p. 74) para dar lugar a outros, fugindo de modelos e experimentando no exercício de criação. Nos encontros com as turmas nas escolas subtraímos elementos que 
Criar Educação, Criciúma, v. 9, ํo 3, ago/dez. 2020 - PPGE - UNESC - ISSN 2317-2452

representavam poder dentro da história de Saint-Exupéry, não com o intuito de fugir do livro ou da história, mas de pensar e produzir possíveis entre formas e formatos fixos.

Para pensar nesse 'entre' convocamos Deleuze e Guattari (2011) que em sua obra 'Mil Platôs: capitalismo e esquizofrenia, volume 1' nos convidam a substituir o verbo 'ser' por uma espécie de gagueira infinita representada pela conjunção 'e... e... e...'. Os autores propõem tal noção ao tomarem do conhecimento do campo biológico a imagem de um rizoma, ou seja, uma antiestrutura que não possui começo, nem fim, mas se encontra sempre no 'entre', de maneira transversal, estabelecendo um contraponto com a ideia de árvore que estabelece uma hierarquia (raiz - caule - copa) de maneira vertical.

\footnotetext{
Entre as coisas não designa uma correlação localizável que vai de uma para outra e reciprocamente, mas uma direção perpendicular, um movimento transversal que as carrega uma e outra, riacho sem início nem fim, que rói suas duas margens e adquire velocidade no meio (DELEUZE; GUATTARI, 2011, p. 49).
}

Nos encontros com as turmas não produzimos movimentos de alternância e nem de comparação, onde um elemento se sobressaísse mais que os outros, mas buscamos com a conjunção 'e' substituir o 'é', que nos dá certeza das coisas, produz afirmações. Assim, percebemos que a substituição do 'ou' fez coexistir os planetas, os baobás e a fabulação, componentes que nos permitiram outras movimentações com o livro sem serem da ordem do melhor, tampouco consideradas verdades únicas e excludentes.

Desse modo, a figura do príncipe apareceu de relance, ou nem mesmo apareceu, isso porque foi dada maior ênfase nas passagens realizadas pelos planetas, por quem os habita, pelos diálogos com personagens sem grandes reconhecimentos. Nos interessou "parir um monstro ou um gigante..." (DELEUZE, 2010, p. 31), de modo que fosse possível apresentar elementos não representativos que produzissem desvios, que fizessem com que 'O Pequeno Príncipe' fosse (re)inventado pelos/as estudantes, sendo outro e singular a cada novo encontro.

\section{Lugares de passagem - a primeira parada}


Fomos sendo potencializados pelos trânsitos entre os planetas e suas singularidades para, também, iniciar nossos percursos pelo território escolar, mas não em linha reta, de modo linear, pelo contrário, fomos ao encontro de teias de pensamentos, palavras e gestos que nos atravessavam. Em nossa parada inicial, desdobramos um projeto de ensino e pesquisa desenvolvido durante a graduação, assumindo a fabulação como método e tendo o livro 'O Pequeno Príncipe' como a materialidade das aulas com uma turma de sexto ano do ensino fundamental em uma escola pública da rede básica de ensino.

Tínhamos como proposta fugir de modelos, de estereótipos, então propusemos que as atividades fossem realizadas em livros encontrados para doação, não fazendo uso das folhas tamanho $A 4$, tampouco dos tradicionais cadernos de desenho. Amparados pela noção livro de artista ${ }^{4}$ (SILVEIRA, 2001) fomos produzindo interferências nas folhas, rasgando, dobrando e, em alguns casos, até mesmo as deixando intactas. Nossa escolha por essa noção se deu pelos livros de artistas possibilitarem trabalhar de maneira intermediática, ou seja, com a inserção de diferentes linguagens e processos artísticos.

Desse modo, realizamos nossos encontros com a turma levando duas versões do livro - 'O Pequeno Príncipe' (SAINT-EXUPÉRY, 2014) e 'O Pequeno Príncipe: livro pop-up' (SAINT-EXUPÉRY, 2015) - em todas as aulas, independente da proposta pensada, apresentando para alguns/algumas essa literatura e proporcionando um reencontro para outros/as. Levamos tinta guache e cola para as atividades de experimentação iniciais, para dar 'uma cara' ao livro, que foi nosso principal suporte durante 0 trimestre. Lançamos algumas atividades mais experimentais nesses primeiros momentos para explorar o livro, as páginas, conhecer esse novo modo de trabalhar com um objeto que muitas vezes só pode ser acessado na biblioteca da escola.

\footnotetext{
${ }^{4}$ Para Silveira (2001), os livros de artistas são entendidos como uma categoria das artes visuais e igualmente produtos desse mesmo campo. Ainda segundo o autor, podem ter quantas etceteras se puder imaginar e não precisam, necessariamente, conter uma sequencialidade, páginas para virar, formatos e tamanhos específicos, de modo que podem ser produzidos para ficarem suspensos, bidimensionais, serem manuseados, interferidos ou somente observados.
} 
Logo percebemos que "Reto e em frente não se pode ir muito longe..." (SAINT-EXUPÉRY, 2014, p. 17). Foi preciso nos desarmar de todos os poderes atribuídos à figura do/a professor/a e se perder no mundo ainda desconhecido da infância, em suas euforias, na curiosidade demagoga e nas atitudes crianceiras.

Ao expor o tema de nossos encontros toda a turma se manifestou, dizendo que já conhecia 'O Pequeno Príncipe', sua história, os personagens, as imagens e até mesmo as frases, pois já tinham tido contato, seja através do livro ou do filme. Como a turma já estava familiarizada com essa literatura foi preciso forçar o pensamento para desmistificar a popularidade ocupada pelo menino viajante e problematizar algumas passagens e atravessamentos provocados por esse livro. Ressaltamos que as atividades desenvolvidas e comentadas nesta escrita se estenderam por vários encontros, tendo em vista o curto período que a disciplina Arte ocupa na grade curricular da maioria das escolas, ou seja, um tempo de 45 minutos, somente uma vez na semana.

Nos primeiros encontros retomamos um pouco da história com o auxílio dos/as estudantes, porém não de modo linear e cronológico. "Recortar, colar, remontar finais, reconstruir os meios, afetar os inícios das histórias para possibilitar a abertura de 'eram muitas vezes', infinitas, contínuas, sempre moventes" (BARIN, 2019 , p. 29) foi o que realizamos ao lembrar certas passagens do livro, inventar outras, seja pelo que as crianças haviam esquecido ou pelos desvios que a leitura de um livro pode provocar em seus/suas leitores/as. Nessa fase introdutória disponibilizamos, além da versão original, a versão de 'O Pequeno Príncipe: livro Pop-Up' (SAINT-EXUPÉRY, 2015), onde foi possível nos demorarmos mais em observar as aquarelas que compõem a história, bem como as camadas que surgem entre elas e os vazios que permitem ver outras coisas.

Insistentemente a turma demonstrou grande interesse em trabalhar com tinta e explorar algumas técnicas de aquarela em seus livros de artista. Nesses movimentos de experimentação e ainda conhecer esse formato diferente de trabalho foram realizadas muitas interferências nas folhas, desde combinações de tintas, água e cola, tinta com restos de folha queimadas, técnicas de escrita ao contrário, misturas de canetas coloridas e até mesmo uma espécie de 'acimentamento', nome 
Criar Educação, Criciúma, v. 9, n 3, ago/dez. 2020 - PPGE - UNESC - ISSN 2317-2452

dado por eles/elas às folhas endurecidas dada a quantidade de tinta depositada sobre elas.

Em outra ocasião distribuímos alguns envelopes que guardavam frases do 'O Pequeno Príncipe' (SAINT-EXUPÉRY, 2014). Nossa intenção era que primeiramente a frase fosse reproduzida tal qual está no livro. ' - Que sem graça', disse um. Optamos por duplicar as frases selecionadas e as separamos em fragmentos. '- Uau, que difícil!', exclamou outra. Desse modo, após a primeira ser igualmente repetida, com os fragmentos que sobraram era possível brincar com palavras soltas, balbuciar, comer algumas letras, criar outras frases.

Foi nesse movimento de fabulação que "E um trem iluminado, roncando como um trovão, fez tremer a cabine do manobreiro" (SAINT-EXUPÉRY, 2008, p. 72) se tornou 'Roncando como um mano breiro do trovão, ilumi nado trem er a trem' (experimentação da proposta). Uma frase criada com as mesmas palavras, porém de outra maneira, esquecendo algumas letras, partindo outras, se perdendo e se achando em seu próprio significado, afinal "a fabulação tem a força da linha de fuga, daquilo que escapa" (MARQUES, 2015, p. 162) e extrapola com os limites impostos pela linguagem ao tornar outras e a cada visita outras.

\section{Lugares de passagem - a viagem continua}

Seguimos as aventuras pelo território escolar propondo algumas alterações e modificações nas propostas e atividades realizadas anteriormente com outros/as estudantes. Nessa etapa, mais do que nunca, sentimos que a fabulação pulsou viva nos encontros com uma turma de ensino não-formal em uma ONG, onde, também por fabulação, surgiram tramas e permitiram tecer linhas de pensamento e criação em meio ao caos.

Uma das maiores dificuldades surgidas durante os encontros, nessa ocasião, foi fugir do referencial, do modelo. Trabalhamos com as ilustrações de ' $O$ Pequeno Príncipe', a partir das quais era preciso produzir outras movimentações, criar novas figuras, subverter o significado atribuído originalmente, contudo, o desejo de permanecer fiel a imagem original em muitos momentos prevaleceu. 
Criar Educação, Criciúma, v. 9, nํ3, ago/dez. 2020 - PPGE - UNESC - ISSN 2317-2452

Notamos que a principal dificuldade surgida foi não copiar a ilustração ou reproduzi-las de modo semelhante. Insistimos para que os momentos de criação sempre estivessem presentes, problematizando as situações que surgiam e instigando as estudantes a buscarem pelo que não estava dado e pronto. Lançamos a proposta de cada uma criar seu planeta, encontrando maneiras de agregar, modular, encaixar os trabalhos realizados para que, aos poucos, em processo, esse mundo ganhasse formas.

Em uma das atividades desenvolvidas dispomos pela sala uma série de ilustrações que compõem os livros 'O Pequeno Príncipe' (SAINT-EXUPÉRY, 2014) e 'O Pequeno Príncipe em Cordel' (LIMEIRA, 2017) e solicitamos que as mesmas fossem fragmentadas em várias partes, de diferentes modos e tamanhos. Seguimos movimentando aquelas dificuldades iniciais em fugir do modelo posto para alimentar a criação de uma nova imagem. Ainda assim, apesar dos vários cortes, das conversas, a presença da ilustração referência estava muito presente e era possível identificarmos alguns elementos das literaturas, como o pôr do sol, a fonte de água, a trilha de formigas.

Ainda diante da persistência de alguns personagens que não desapareciam ou se transformavam em outros, repetimos esse movimento mais algumas vezes, de diversas maneiras, sendo uma delas a utilização de linha e agulha para costurar. Os pedaços já fragmentados, unidos e agora desmembrados novamente aos poucos foram ganhando novos formatos, novas caras e personagens que não conseguimos identificar sem uma pitada de fabulação.

Em outra ocasião, convidamos três versões diferentes sobre a história: 'O Pequeno Príncipe' (SAINT-EXUPÉRY, 2014), 'O Pequeno Príncipe: livro pop-up' (SAINT-EXUPÉRY, 2015) e 'O Pequeno Príncipe em Cordel' (LIMEIRA, 2017) para adentrarem nosso encontro. Essa proposta consistiu em realizar um desenho duplicando uma ilustração do livro, onde no início era permitido sobrepor algum material que fosse possível copiar a imagem selecionada, repetindo linha por linha, traço por traço, até que em determinado momento os livros foram 'roubados', ficando a cargo das estudantes continuar o desenho, criando outras coisas a partir das 
Criar Educação, Criciúma, v. 9, n 3, ago/dez. 2020 - PPGE - UNESC - ISSN 2317-2452

linhas que haviam sido esboçadas e que com esse movimento de captura da referência, ficaram à deriva.

Foi preciso esforço para criar novos personagens: metade rei e metade árvore, paisagens de planetas frequentados por unicórnios e flores com pétalas duras e multicoloridas. A fabulação foi nossa grande aliada para realizar essas movimentações, afinal foi necessário exercitar um constante ato de criação, se desprender de modelos e fugir da cópia para criar novas imagens, personagens estrangeiros e diálogos outros, movimentos que, por vezes, causaram incômodos, desassossegos, mas que foram indispensáveis para seguir pulverizando os encontros com o inesperado, causando fulgurações nas aulas, atividades e no pensamento.

\section{Linha por linha, um ponto (quase) final}

Nestas linhas da escrita apresentamos algumas considerações e recortes acerca do processo de trabalho com o 'O Pequeno Príncipe' a partir da fabulação. Partimos das ideias de desmistificar alguns discursos naturalizados, hegemônicos muitas vezes tomados como bordões e clichês no senso comum e também na área da educação, onde essa literatura cumpre uma função de autoajuda e moralizadora.

Acolher a fabulação como método para compor a escrita foi como tomar fôlego, como olhar para a vida sob outras lentes. Com e através dessa noção aproveitamos "uma migração de pássaros selvagens para fugir" (SAINT-EXUPÉRY, 2014 , p. 37) da mesmice, do comodismo, daquilo que não nos desconcertava. Contudo, nos caminhos trilhados também encontramos muitas sementes de baobás e fomos perfurados, afetados por suas raízes. Procuramos não nos livrar delas, dos baobás, e sim resistir com eles, resistir através da fabulação, com a criação de um povo que falta. Resistir por/em linhas de fuga que atravessaram caminhos e modelos para se reinventar, que nos permitiram respirar quando algo sufocava, que nos tirava do lugar comum para criar uma viagem no interior da sala de aula, das nossas casas, do próprio corpo e nos acometer para novas descobertas.

Embarcamos nessa viagem e visitamos diferentes planetas, às vezes pelas bordas, outras pelo meio. Nossa passagem por alguns foi bem repentina e nada 
Criar Educação, Criciúma, v. 9, ํo 3, ago/dez. 2020 - PPGE - UNESC - ISSN 2317-2452

demorada, enquanto por outros, como aquele tão pequeno em "Que três passos dão-lhe a volta" (LIMEIRA, 2017, p. 94) e o acender e apagar do lampião faz os dias durarem um minuto (SAINT-EXYPÉRY, 2014), fizemos morada por alguns dias, afinal, nesse era possível vermos os pores do sol que tanto nos potencializaram infinitas vezes.

Nosso desafio foi pensar em como operar com a literatura de 'O Pequeno Príncipe' (SAINT-EXUPÉRY, 2014) na educação em diferentes espaços educativos. Forçamos o pensamento para não impelir somente movimentos de paixão e encantamento pela referida literatura, mas para nos afetar de outras maneiras. Nesse percurso, fomos potencializados por essa literatura e também pelas tramas, nós, amarrações que desfizemos e refizemos com as aventuras do menininho de cabelos cor de trigo.

Em nossas aventuras conjuntas com os/as estudantes, desterritorializamos a linguagem que era apresentada e brincamos com as palavras, numa espécie de gagueira infinita, em exercícios de videntes e ouvidores. Intentamos o que Deleuze (2011) menciona como finalidade da literatura: pedir passagem de vida na/pela linguagem.

Com a fabulação foi possível desenvolvermos movimentos com a literatura sem que entrássemos em significações estereotipadas, de um lugar-comum. Alguns aprenderam invencionar frases, comer letras na própria escrita, outros criaram livros em caixas, envelopes e planetas, de maneiras distintas, coloridas ou sem cores. Nesses movimentos insistimos coletivamente em permanecer em movimento, buscando pelos momentos em que a criação aparece e "todas as estrelas riem docemente" (SAINT-EXUPÉRY, 2008, p. 91) não deixando outra alternativa senão fabular e... fabular e... fabular e... para (re) existir de outras tantas formas.

\section{Referências}

BARIN, Ana Cláudia. Invento-me: potências do devir-criança - Uma educação pela fabulação. Tese (Doutorado em Educação). Pós-Graduação em Educação, Universidade Federal de Santa Maria, Rio Grande do Sul, 2019.

DELEUZE, Gilles; GUATTARI, Félix. Mil Platôs: capitalismo e esquizofrenia. Tradução de Aurélio Guerra Neto e Celia Pinto Costa. São Paulo: Ed. 34, 1995. 
DELEUZE, Gilles; GUATTARI, Félix. O que é a filosofia?. Tradução de Bento Prado Jr. e Alberto Alonso Muñoz. 3a. ed. São Paulo: Editora 34, 2010.

DELEUZE, Gilles; GUATTARI, Félix. Mil platôs: capitalismo e esquizofrenia. Tradução de Ana Lúcia de Oliveira, Aurélio Guerra Neto e Celia Pinto Costa. Vol. 1. $2^{\mathrm{a}}$ ed., São Paulo: Editora 34, 2011.

DELEUZE, Gilles; GUATTARI, Félix. Kalka: por uma literatura menor. Tradução de Cíntia Vieira da Silva. 1 ed.; 3 reimp. Belo Horizonte: Autêntica Editora, 2017.

DELEUZE, Gilles; PARNET; Claire. Diálogos. Tradução de Eloisa Araújo Ribeiro. São Paulo: Escuta, 1998.

DELEUZE, Gilles. Sobre o teatro: Um manifesto de menos; O esgotado. Tradução de Fátima Saadi, Ovídio de Abreu, Roberto Machado. Rio de Janeiro: Jorge Zahar Ed., 2010.

DELEUZE, Gilles. Crítica e clínica. Tradução de Peter Pál Pelbart. 2ª . ed. São Paulo: Editora 34, 2011.

DELEUZE, Gilles. Conversações. Tradução de Peter Pál Pelbart. 3ª . ed. São Paulo: Editora 34, 2013.

LIMEIRA, Josué. O Pequeno Príncipe em Cordel. 2ª Ed. Recife: Editora Cativar, 2017.

MARQUES, Davina. Entre fabulações de uma formação docente. Revista Digital do LAV, SM, v. 8, n. 2, p. 160 - 174, mai./ago. 2015.

OLIVEIRA, Marilda Oliveira de. Diário de aula como instrumento metodológico da prática educativa. Revista Lusófona de Educação, v. 27, n. 27, p. 111-126, nov. 2014.

OLIVEIRA, Marilda Oliveira de. Por uma Abordagem Narrativa e Autobiográfica: os diários de aula como foco de investigação. In: MARTINS, Raimundo; TOURINHO; Irene (Orgs.). Educação da cultura visual: conceitos e contextos. Santa Maria: Ed. Da UFSM, p. 175-190, 2011.

SAINT-EXUPÉRY, Antoine. O pequeno príncipe: livro pop-up. Tradução de Dom Marcos Barbosa. 48ª Ed. Rio de Janeiro, Agir, 2015.

SAINT-EXUPÉRY, Antoine. O pequeno príncipe. Tradução de Dom Marcos Barbosa. 48ª Ed. Rio de Janeiro, Agir, 2014.

SAINT-EXUPÉRY, Antoine. O pequeno príncipe. Tradução de Dom Marcos Barbosa. Ed. rev. Rio de Janeiro: PocketOuro, 2008. 
SILVEIRA, Paulo. A página violada: da ternura a injúria na construção de livro de artista. Porto Alegre: Editora da Universidade/UFRGS, 2001.

Recebido maio de 2020

Aprovado setembro de 2020 